\title{
High-Throughput Sequence Determination of Cyclic Peptide Library Members by Partial Edman Degradation/Mass Spectrometry
}

\author{
Sang Hoon Joo, Qing Xiao, Yun Ling, Bhaskar Gopishetty, and Dehua Pei*
}

\section{Supporting Information}

Figure S1. MALDI-TOF MS spectra of 8 cyclic peptides individually synthesized on Rink amide resin. Crude peptides were dissolved in DMSO and diluted in 0.01\% TFA in water. One $\mu \mathrm{L}$ of the peptide solution was mixed with $2 \mu \mathrm{L}$ of saturated 4-hydroxy- $\alpha$-cyanocinnamic acid in acetonitrile/0.1\% TFA (1:1) and $1 \mu \mathrm{L}$ of the mixture was spotted onto a MALDI sample plate. The peptide sequence, the calculated mass for pseudomolecular ion (M), and the observed $\mathrm{m} / \mathrm{z}$ values are indicated in each spectrum. Nle, norleucine; fF, p-fluorophenylalanine; meF, $N^{\alpha}$ methylphenylalanine.

Figure S2. HPLC and MS analysis of linear and cyclic peptide AVWmeFRRVQ. Panel $a$, HPLC chromatogram of crude linear peptide. The desired product had a $t_{R}$ of $14.3 \mathrm{~min}$. The impurities at $t_{R}=19.6$ and 21.0 min were peptides containing incompletely deprotected arginine side chains. Panel $b$, HPLC chromatogram of crude cyclo(AVWmeFRRVQ). Panel $c$, HPLC chromatogram of 1.33:1 mixture of cyclic/linear peptides. Panel $d$, MALDI-TOF MS of the peptide mixture from $c$.

HPLC condition: Analytical HPLC was run on $\mathrm{C}_{18}$ column (Vydac 218TP54; 4.6 mm i.d x 250 mm length) with a gradient formed from A: 0.05\% TFA in water, B: $0.05 \%$ TFA in acetonitrile using UV detection ( $280 \mathrm{~nm}$ ) by Waters 486 tunable absorbance detector. The crude peptides were dissolved in DMSO to the concentration of $10 \mathrm{mg} / \mathrm{mL}$ and diluted in HPLC solvent (80\% A). Each injection contained $200 \mu \mathrm{L}$ sample (3\% DMSO) and the column was eluted with a gradient of $20 \%$ to $80 \% \mathrm{~B}$ in $30 \mathrm{~min}$ at $1 \mathrm{~mL} / \mathrm{min}$.

Figure S3. HPLC and MS analysis of linear and cyclic peptide AVWfFRRVQ. Panel a, HPLC chromatogram of crude linear peptide. The desired product had a $t_{R}$ of $13.8 \mathrm{~min}$. The impurity at $t_{R}=21.9$ min was the peptide containing one incompletely deprotected arginine side chain. Panel $b$, HPLC chromatogram of crude cyclo(AVWfFRRVQ). Panel c, HPLC chromatogram of 0.97:1 mixture of cyclic/linear peptides. Panel $d$, MALDI-TOF MS of the peptide mixture from $c$. HPLC conditions were the same as in Figure S2.

Table S1. Comparison of the ionization efficiencies of linear and cyclic peptides in MALDI MS. The 1.33:1 (mol/mol) mixture of cyclo(AVWmeFRRVQ) and the corresponding linear peptide (from Figure S2) was dissolved in $0.1 \%$ TFA solution to make $36 \mu \mathrm{M}$ and $18 \mu \mathrm{M}$ solutions. Each solution was mixed with two volumes of saturated 4-hydroxy- $\alpha$-cyanocinnamic acid in acetonitrile/0.1\% TFA and spotted 10 times onto a MALDI sample plate ( $1 \mu \mathrm{L}$ each spot). The samples were analyzed in a Bruker Reflex III MALDI-TOF instrument in an automated format. The ratios of cyclic/linear peptide ionization efficiencies were calculated from the MALDI peak areas. The "average" ratio was the mean from 10 parallel experiments. An "average*” value was also calculated after excluding the highest and lowest values and corrected by a factor of 1.33 
(cyclic/linear peptide molar ratio). The same experiments were repeated for cyclo(AVWfFRRVQ) and the linear counterpart.

Figure S4. MALDI-TOF MS spectra of 20 randomly selected beads from the cyclic peptide library (trial No. 2 in Table 2).

Figure S5. Binding of SA-AP to immobilized peptide cyclo(GTHPQALE) in the presence of increasing concentrations of free cyclic and linear peptides. The amount of SA-AP activity retained by the affinity resin was plotted against soluble competitor peptide concentration. The IC $_{50}$ value represents the concentration at which $50 \%$ of SA-AP activity was retained by the resin (relative to that in the absence of competitor peptide).

Figure S6. MALDI-TOF spectra of 5 randomly picked beads from the tyrocidine analog library. $\mathrm{M}_{1}$, cyclic peptide; $\mathrm{M}_{2}$, linear encoding peptides.

Figure S7. HPLC and MALDI-TOF analysis of 8 individually synthesized tyrocidine analogs. Peptides were synthesized by anchoring Asp $^{5}$ onto NovaSynTGA resin (90 $\left.\mu \mathrm{m}, 0.23 \mathrm{mmol} / \mathrm{g}\right)$ and cyclized between $\operatorname{Gln}^{6}$ and $\mathrm{Asp}^{5}$. HPLC was run on Varian Dynamax $\mathrm{C}_{18}$ column (10.0 mm id x $250 \mathrm{~mm}$ length). Peptides were dissolved in $80 \% \mathrm{H}_{2} \mathrm{O}$ and $20 \% \mathrm{CH} 3 \mathrm{CN}$ containing $0.05 \%$ TFA or in pure DMSO for injection. The column was eluted with linear gradients of $\mathrm{CH}_{3} \mathrm{CN}$ in water (both containing $0.05 \%$ TFA) as indicated in each chromatogram. Flow rate was $2 \mathrm{~mL} / \mathrm{min}$. Detection was at $214 \mathrm{~nm}$, with a Waters 486 tunable absorbance detector. 
Figure S1. MALDI spectra of 8 crude, individually synthesized cyclic peptides
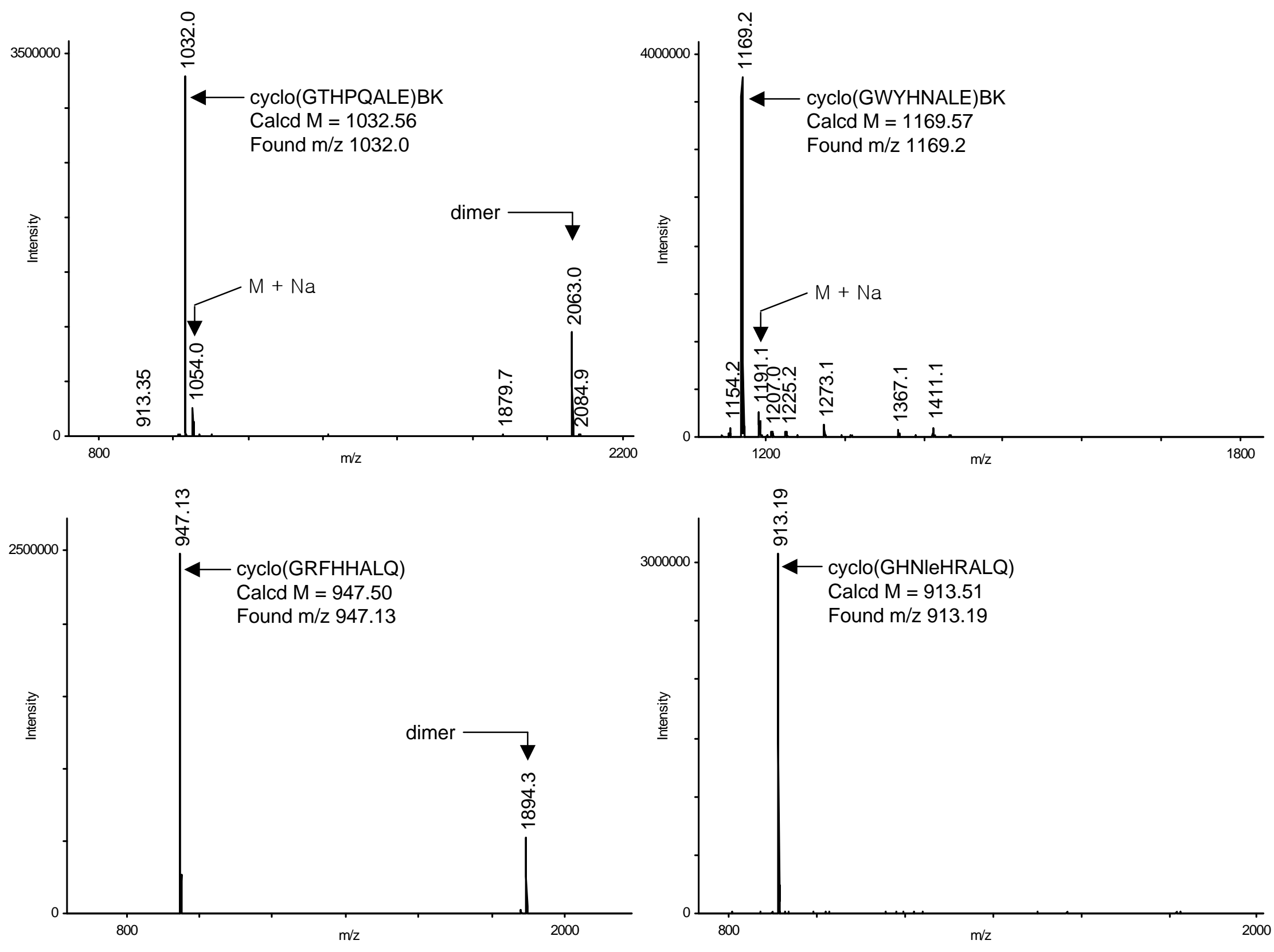


\section{Figure S1 (cont'd)}
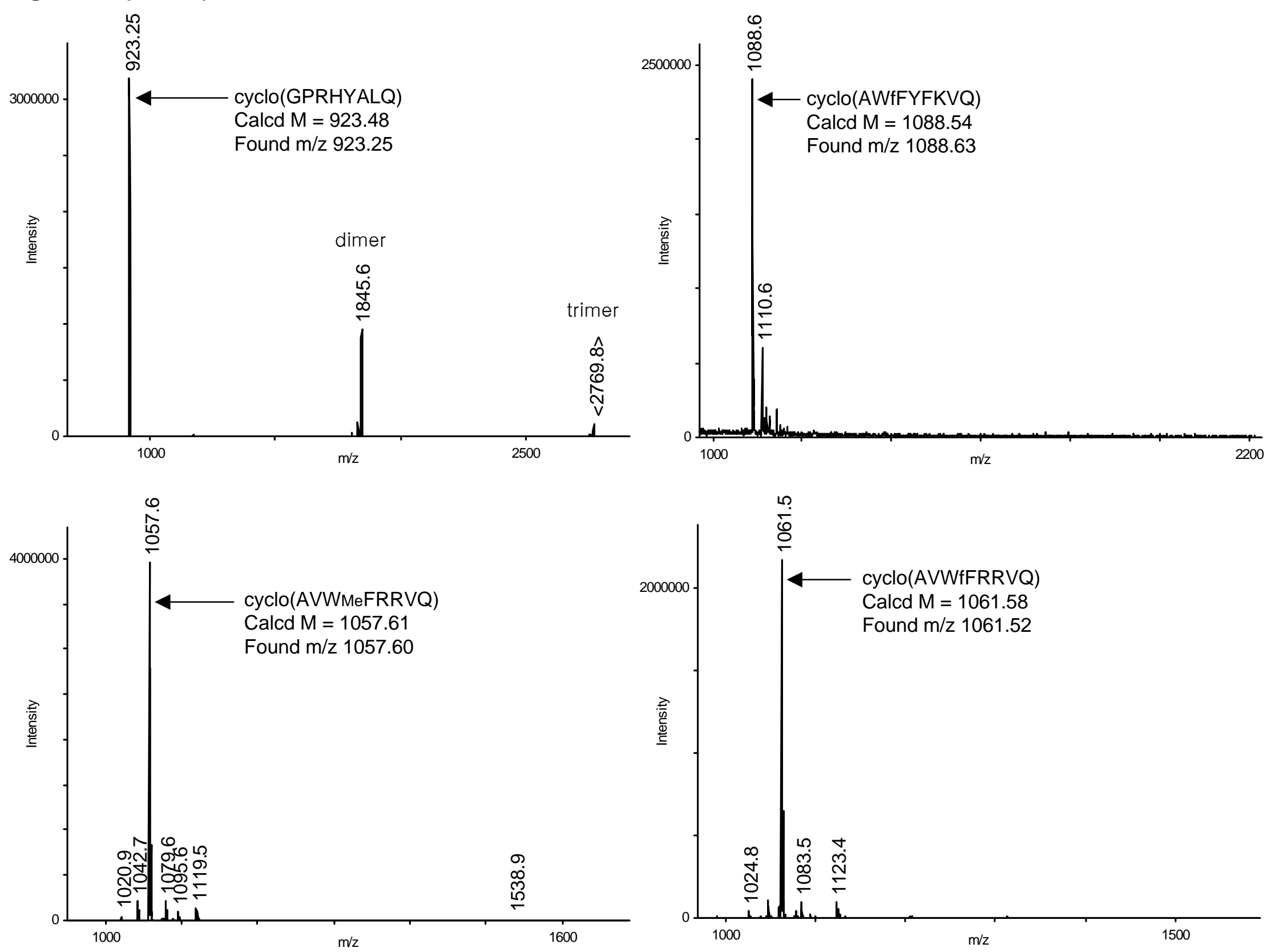
Figure S2. HPLC (a-c) and MALDI MS (d) analysis of linear and cyclic peptide (AVWmeFRRVQ).
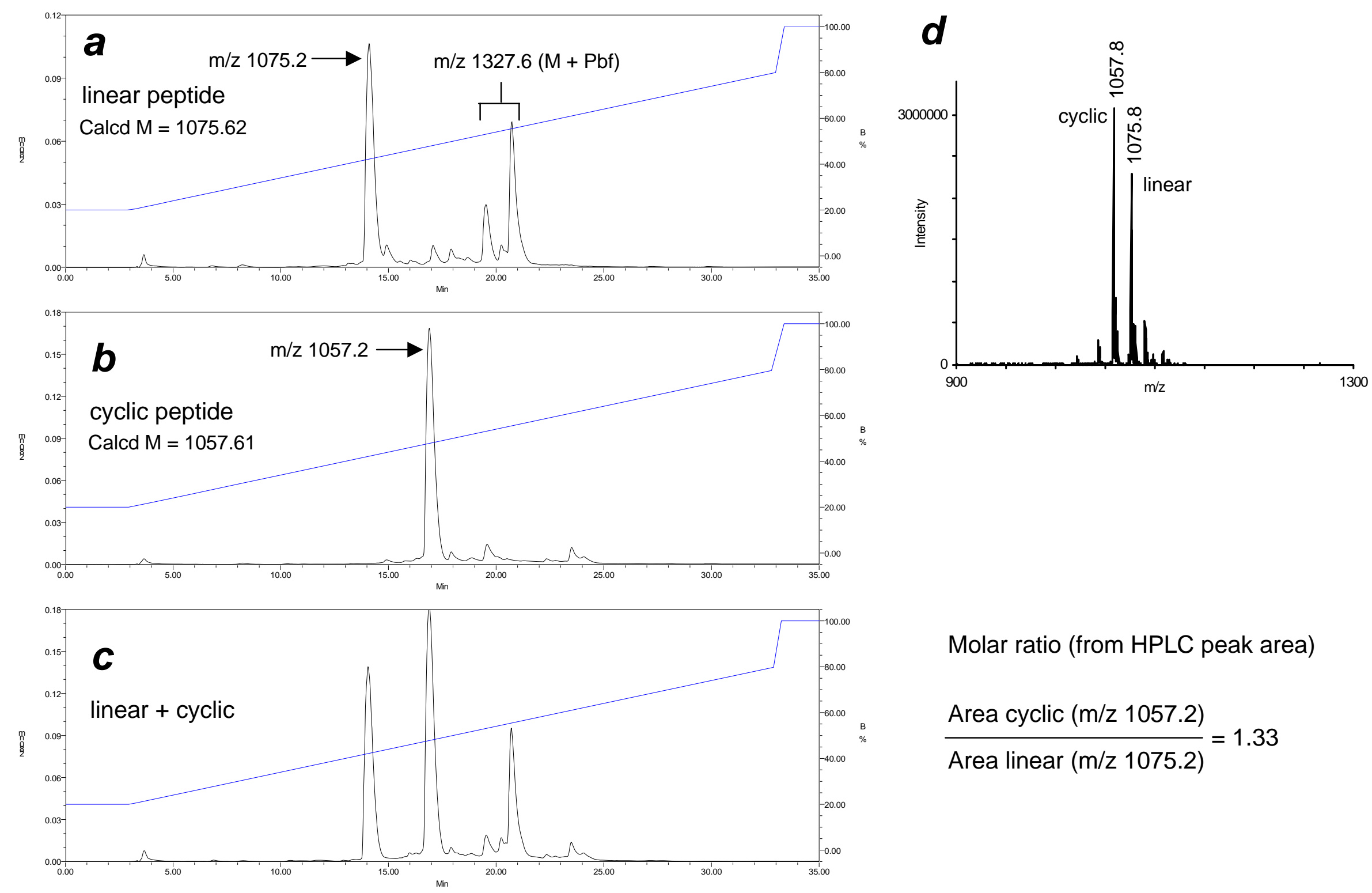

Molar ratio (from HPLC peak area)

Area cyclic (m/z 1057.2)

$\frac{\text { Area linear }(\mathrm{m} / \mathrm{z} \text { 1075.2) }}{\text { A }}=1.33$ 
Figure S3. HPLC (a-c) and MALDI MS (d) analysis of linear and cyclic peptide (AVWfFRRVQ).
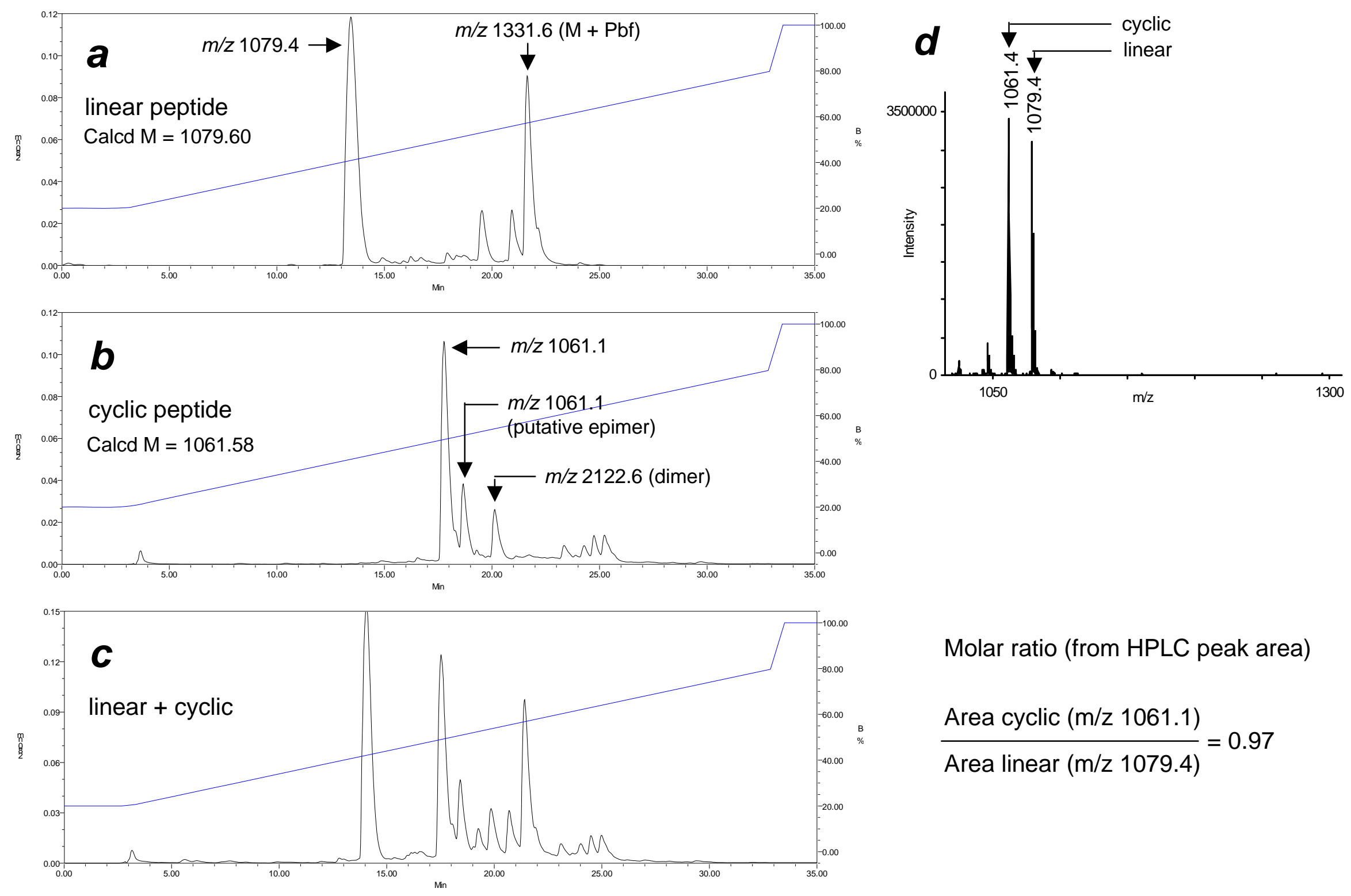

Molar ratio (from HPLC peak area)

Area cyclic (m/z 1061.1)

$\overline{\text { Area linear }(\mathrm{m} / \mathrm{z} \text { 1079.4) }}=0.97$ 
Table S1. Comparison of ionization efficiency of linear vs cyclic peptides in MALDI MS

\begin{tabular}{|c|c|c|c|c|c|c|c|c|c|c|c|c|c|c|c|}
\hline \multicolumn{8}{|c|}{ cyclo(AVWfFRRVQ) } & \multicolumn{8}{|c|}{ cyclo(AVWmeFRRVQ) } \\
\hline \multicolumn{4}{|c|}{ Each spot contained $~ 12$ pmol peptides } & \multicolumn{4}{|c|}{ Each spot contained $\sim 6$ pmol peptides } & \multicolumn{4}{|c|}{ Each spot contained $\sim 12$ pmol peptides } & \multicolumn{4}{|c|}{ Each spot contained $\sim 6 \mathrm{pmol}$ peptides } \\
\hline sample & $\begin{array}{l}\text { Area } \\
\text { Cyclic }\end{array}$ & $\begin{array}{l}\text { Area } \\
\text { Linear }\end{array}$ & $\begin{array}{l}\text { Cyclic/ } \\
\text { Linear }\end{array}$ & sample & $\begin{array}{l}\text { Area } \\
\text { Cyclic }\end{array}$ & $\begin{array}{l}\text { Area } \\
\text { Linear }\end{array}$ & $\begin{array}{l}\text { Cyclic/ } \\
\text { Linear }\end{array}$ & sample & $\begin{array}{l}\text { Area } \\
\text { Cyclic }\end{array}$ & $\begin{array}{l}\text { Area } \\
\text { Linear }\end{array}$ & $\begin{array}{l}\text { Cyclic/ } \\
\text { Linear }\end{array}$ & sample & $\begin{array}{l}\text { Area } \\
\text { Cyclic }\end{array}$ & $\begin{array}{l}\text { Area } \\
\text { Linear }\end{array}$ & $\begin{array}{l}\text { Cyclic/ } \\
\text { Linear }\end{array}$ \\
\hline A11 & 1282 & 7151 & 0.179 & B1 & 1248 & 2376 & 0.525 & C11 & 6436 & 2524 & 2.550 & D1 & 1265 & 3675 & 0.344 \\
\hline A12 & 1901 & 2765 & 0.688 & B2 & 351 & 1729 & 0.203 & $\mathrm{C} 12$ & 7222 & 4722 & 1.529 & D2 & 3424 & 3723 & 0.920 \\
\hline A13 & 6307 & 4695 & 1.343 & B3 & 567 & 8280 & 0.068 & $\mathrm{C} 13$ & 9014 & 10414 & 0.866 & D3 & 1333 & 3466 & 0.385 \\
\hline A14 & 3275 & 1899 & 1.725 & B4 & 3033 & 9209 & 0.329 & C14 & 2445 & 3230 & 0.757 & D4 & 5533 & 9959 & 0.556 \\
\hline A15 & 8004 & 3953 & 2.025 & B5 & 2234 & 7101 & 0.315 & $\mathrm{C} 15$ & 3468 & 3635 & 0.954 & D5 & 1117 & 1802 & 0.620 \\
\hline $\mathrm{A} 16$ & 976 & 2181 & 0.448 & $\mathrm{~B} 6$ & 86 & 1974 & 0.044 & $\mathrm{C} 16$ & 2575 & 4326 & 0.595 & D6 & 4601 & 7020 & 0.655 \\
\hline A17 & 1776 & 7776 & 0.228 & $\mathrm{~B} 7$ & 580 & 5058 & 0.115 & $\mathrm{C} 17$ & 3865 & 4430 & 0.872 & D7 & 2665 & 4801 & 0.555 \\
\hline A18 & 4961 & 3379 & 1.468 & B8 & 325 & 4671 & 0.070 & $\mathrm{C} 18$ & 3567 & 1531 & 2.330 & D8 & 197 & 352 & 0.560 \\
\hline A19 & 205 & 2589 & 0.079 & B9 & 2932 & 4012 & 0.731 & $\mathrm{C} 19$ & 3011 & 1487 & 2.025 & D9 & 6717 & 6237 & 1.077 \\
\hline $\mathrm{A} 20$ & 7213 & 9222 & 0.782 & B10 & 849 & 2545 & 0.334 & $\mathrm{C} 20$ & 755 & 124 & 6.089 & $\mathrm{D} 10$ & 4768 & 291 & 16.385 \\
\hline \multicolumn{2}{|c|}{ Average } & \multicolumn{2}{|c|}{$0.90 \pm 0.70$} & \multicolumn{2}{|c|}{ Average } & \multicolumn{2}{|c|}{$0.27 \pm 0.22$} & \multicolumn{2}{|c|}{ Average } & \multicolumn{2}{|c|}{$1.9 \pm 1.6$} & \multicolumn{2}{|c|}{ Average } & \multicolumn{2}{|c|}{$2.2 \pm 5.0$} \\
\hline \multicolumn{2}{|c|}{ Average $^{\star}$} & \multicolumn{2}{|c|}{$0.86 \pm 0.59$} & \multicolumn{2}{|c|}{ Average $^{\star}$} & \multicolumn{2}{|c|}{$0.24 \pm 0.16$} & \multicolumn{2}{|c|}{ Average $^{\star}$} & \multicolumn{2}{|c|}{$1.5 \pm 0.7$} & \multicolumn{2}{|c|}{ Average* $^{\star}$} & \multicolumn{2}{|c|}{$0.67 \pm 0.22$} \\
\hline \multicolumn{4}{|c|}{$\begin{array}{l}\text { After correction of molar ratio } \\
\text { (based on HPLC peak area) }\end{array}$} & \multicolumn{4}{|c|}{$\begin{array}{l}\text { After correction of molar ratio } \\
\text { (based on HPLC peak area) }\end{array}$} & \multicolumn{4}{|c|}{$\begin{array}{l}\text { After correction of molar ratio } \\
\text { (based on HPLC peak area) }\end{array}$} & \multicolumn{4}{|c|}{$\begin{array}{l}\text { After correction of molar ratio } \\
\text { (HPLC peak area) }\end{array}$} \\
\hline \multicolumn{2}{|c|}{ Average } & \multicolumn{2}{|c|}{$0.92 \pm 0.71$} & \multicolumn{2}{|c|}{ Average } & \multicolumn{2}{|c|}{$0.28 \pm 0.22$} & \multicolumn{2}{|c|}{ Average } & \multicolumn{2}{|c|}{$1.4 \pm 1.2$} & Averc & & $1.6 \pm$ & \\
\hline Aver & & $0.87 \pm$ & & Avera & & $0.25 \pm$ & & & age* & $1.1 \pm C$ & & Avera & & $0.50 \pm$ & \\
\hline
\end{tabular}

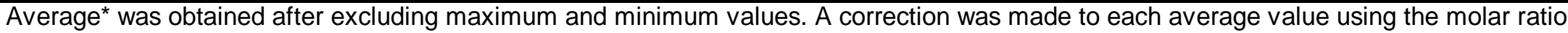
obtained from HPLC peak area. 
Figure S4.

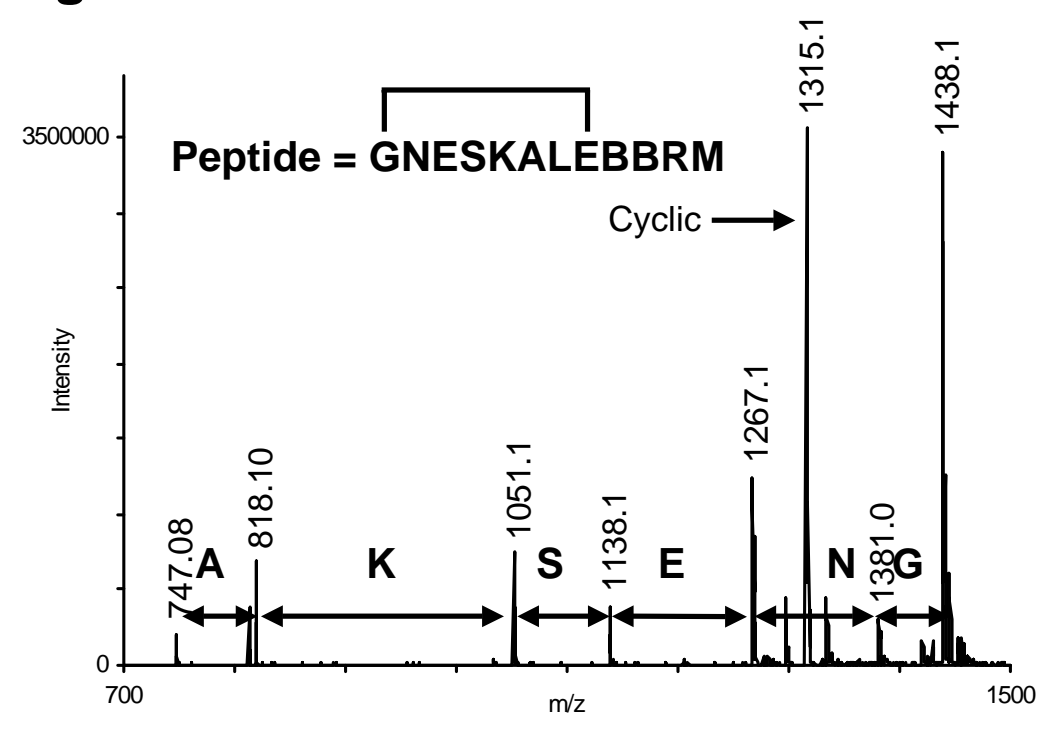

Z:ISang HoonIMaldi datal1010SJ101005I0_L1|1\1SReflpdatal1\1r ।

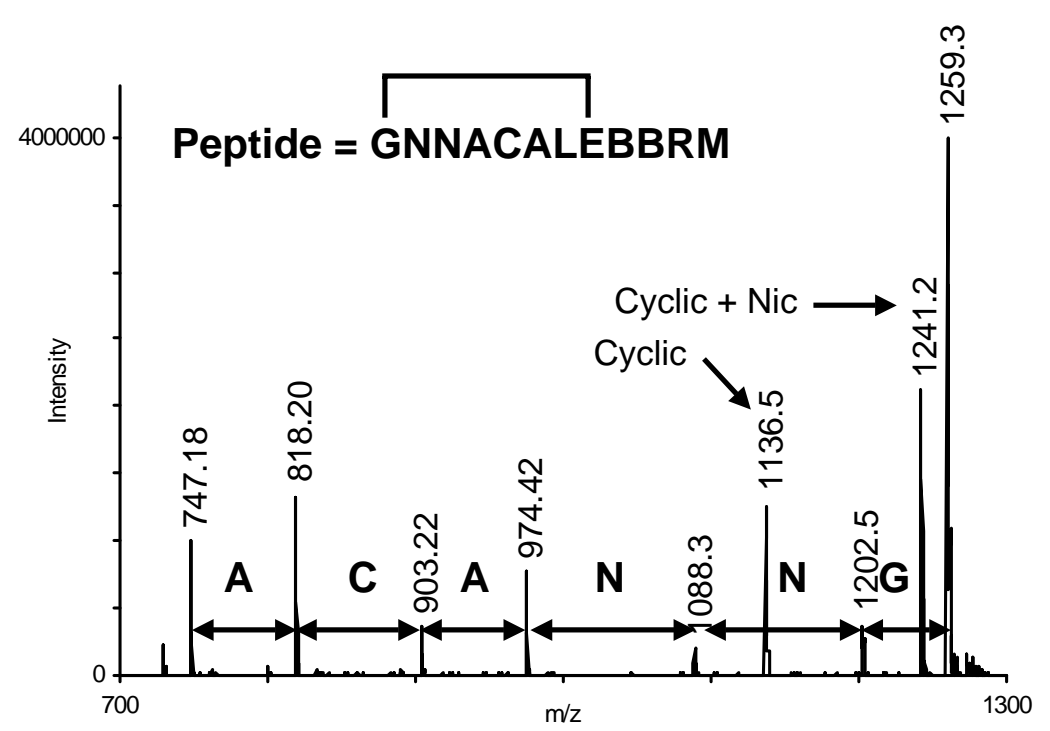

Z:ISang HoonIMaldi datal1010SJ101005।0_L3\1\1SReflpdatal1\1r ।

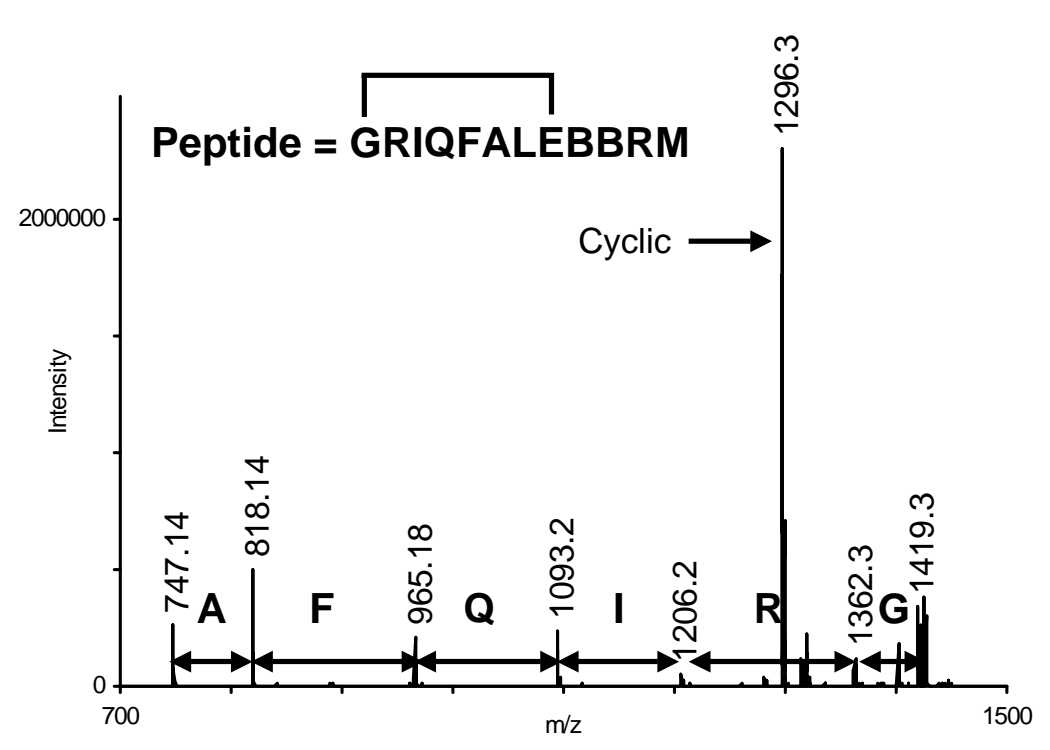

Z:ISang Hoon\Maldi datal1010SJ101005I0_L2\1\1SReflpdatal1\1r ।

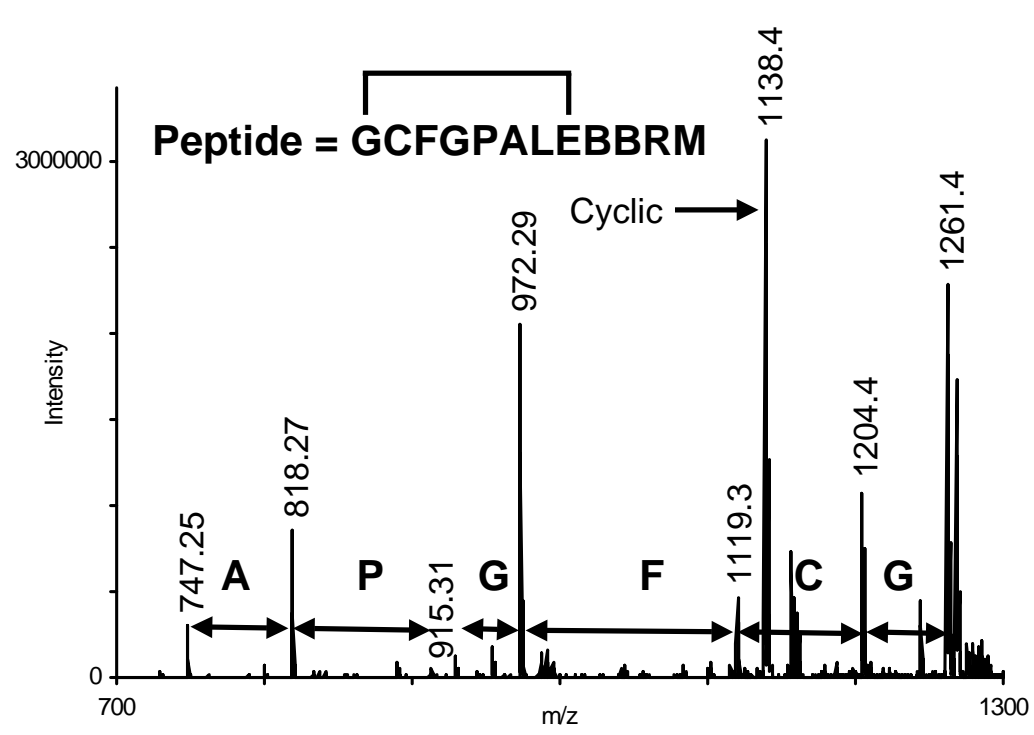

Z:ISang HoonIMaldi datal1010SJ101005I0_L4\1\1SReflpdatal1\1r 
Figure S4 (cont'd)

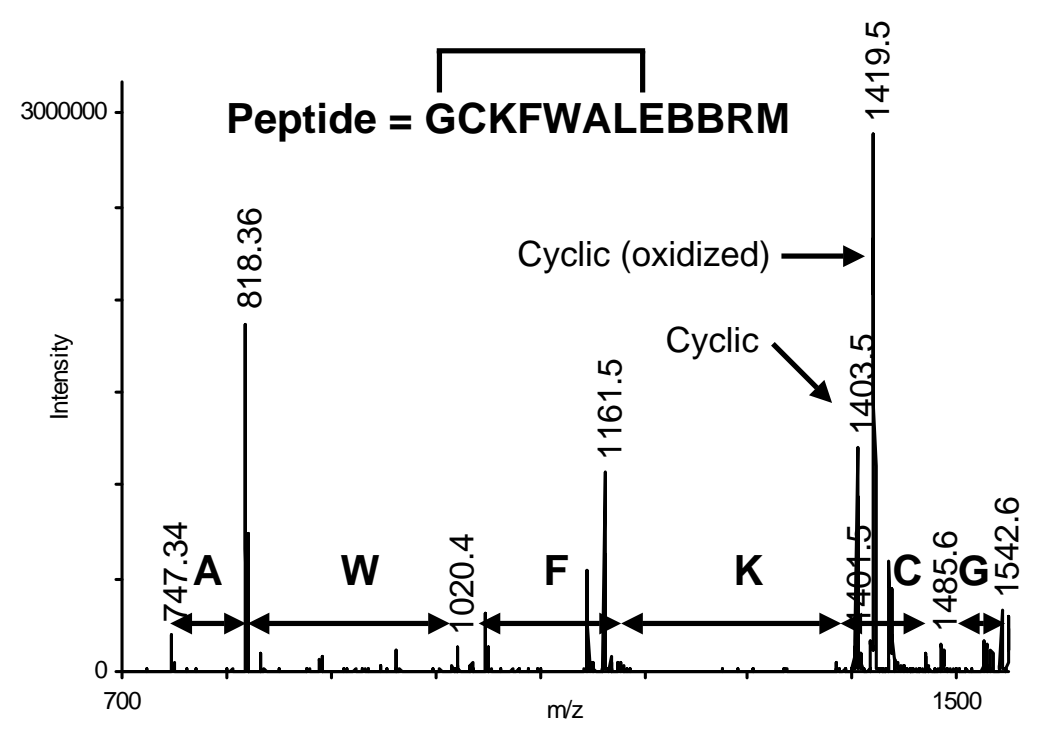

Z:ISang HoonIMaldi datal1010SJ101005I0_L5I1|1SReflpdatal111r ।

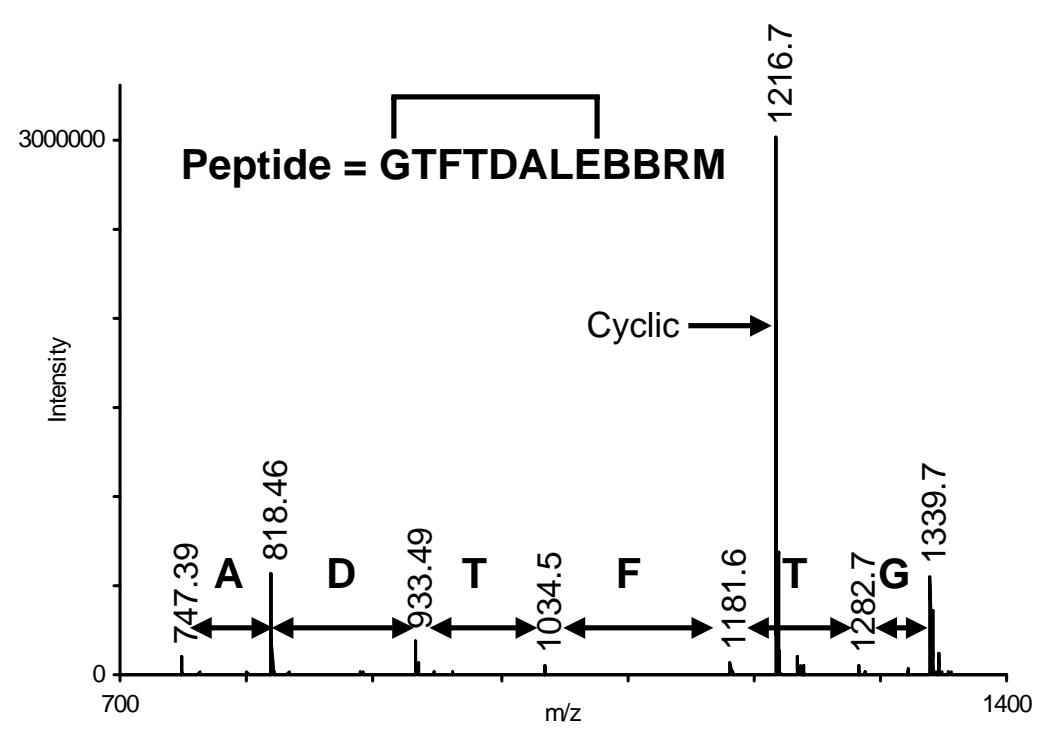

Z:ISang HoonIMaldi datal1010SJ101005।0_L7\1|1SReflpdatal111r ।

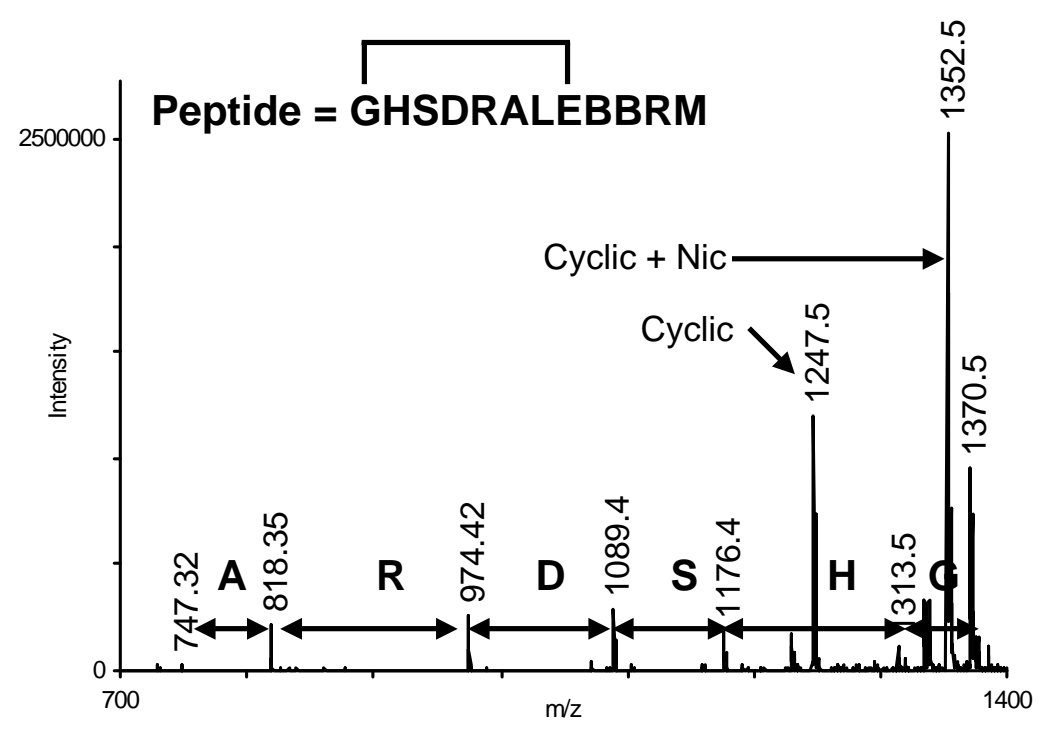

Z:ISang HoonlMaldi datal1010SJ101005I0_L6I1|1SReflpdatal111r ।

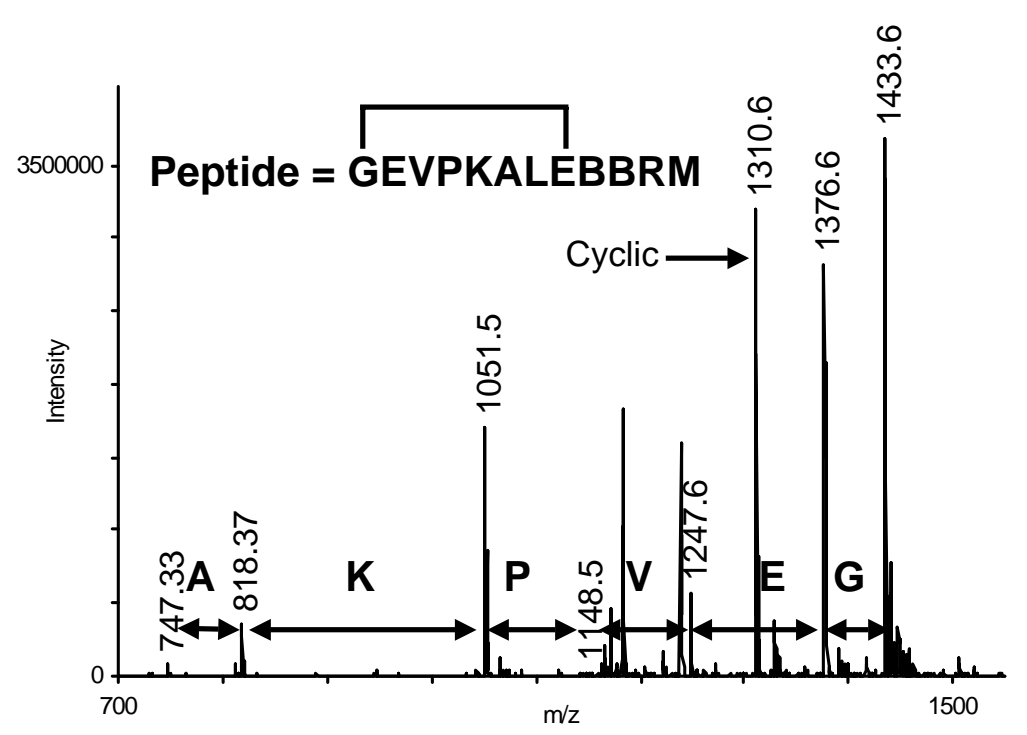

Z:ISang HoonIMaldi datal1010SJ10100510_L8I111SReflpdatal111r । 
Figure S4 (cont'd)

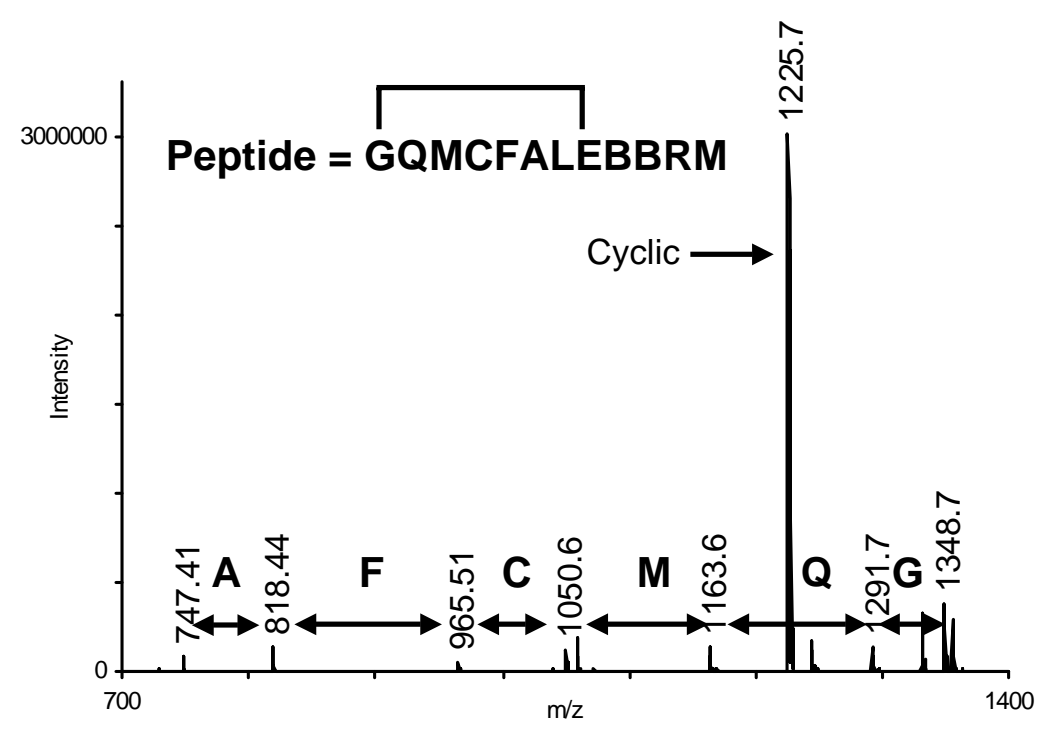

Z:ISang HoonIMaldi datal1010SJ101005I0_L9\1\1SReflpdatal1\1r

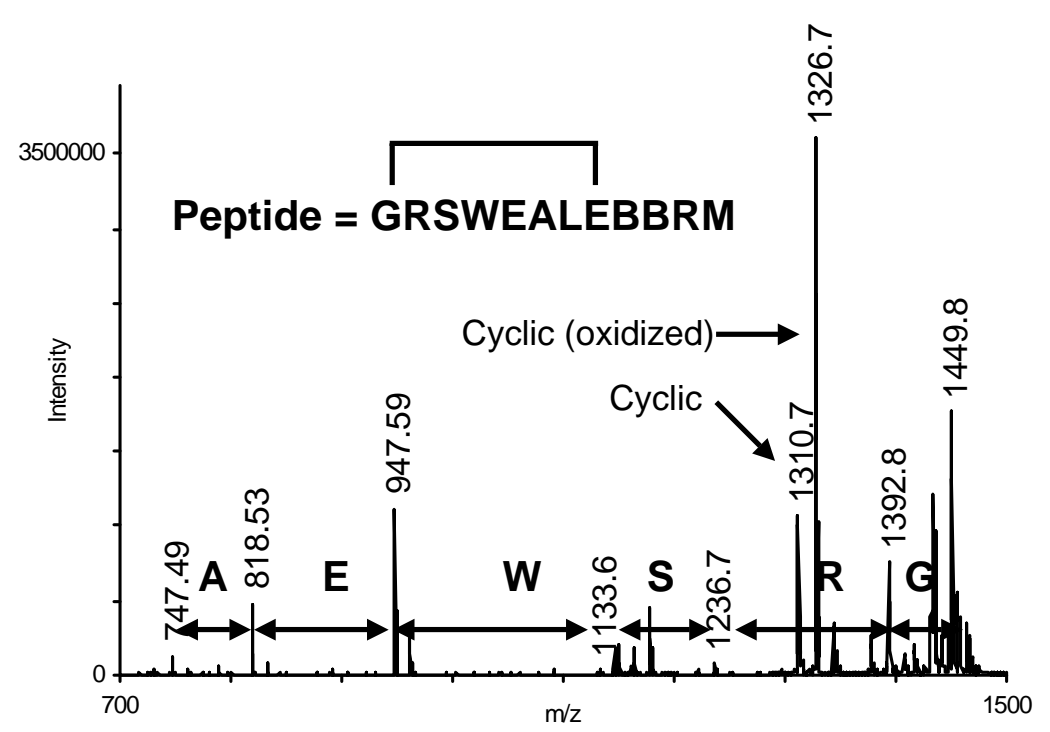

Z:ISang HoonIMaldi datal1010SJ10100510_L11\1\1SReflpdatal111r

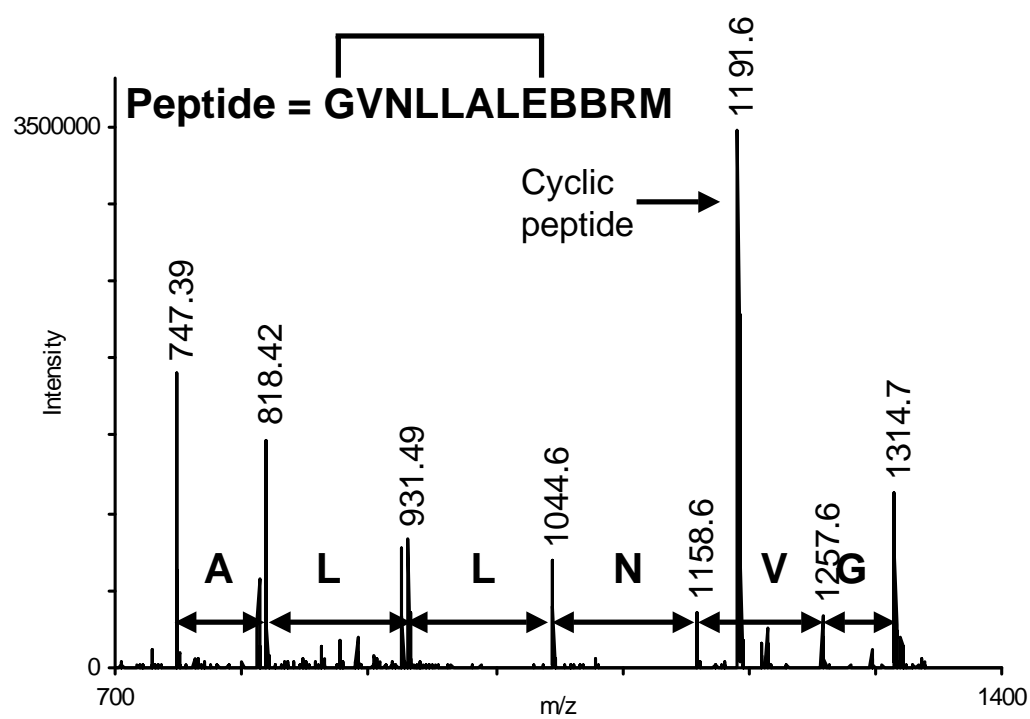

Z:ISang HoonIMaldi datal1010SJ101005।0_L10।1\1SReflpdatal1\1r

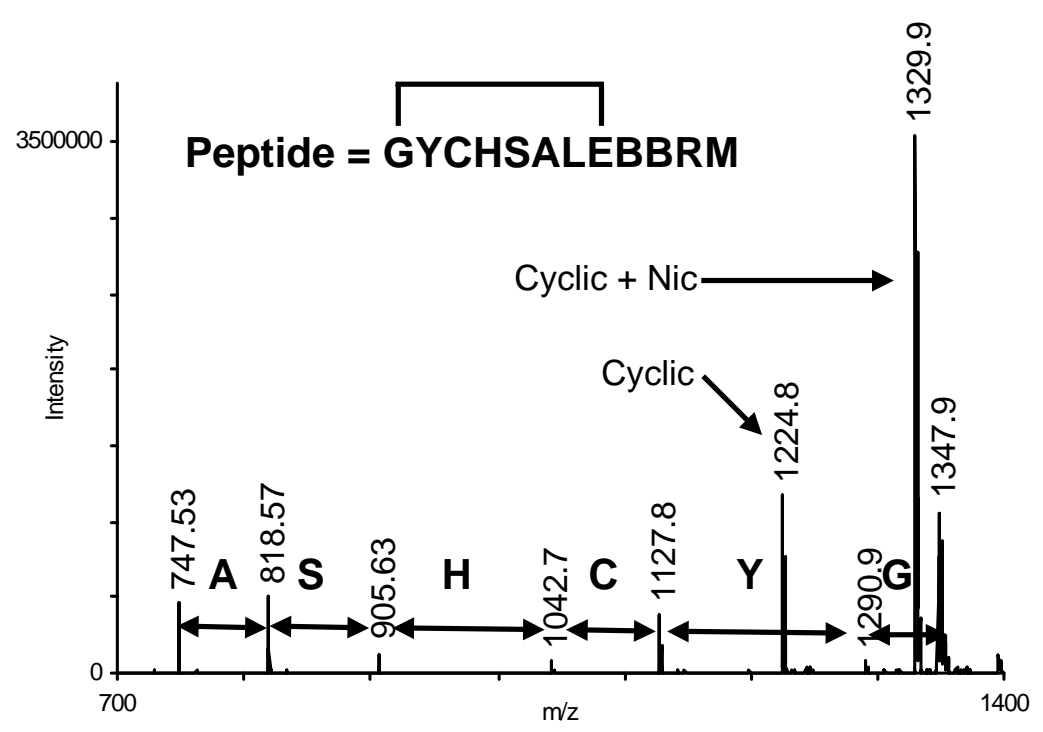

Z:ISang Hoon\Maldi datal1010SJ101005।0_L12\1\1SReflpdatal1\1r 


\section{Figure S4 (cont'd)}

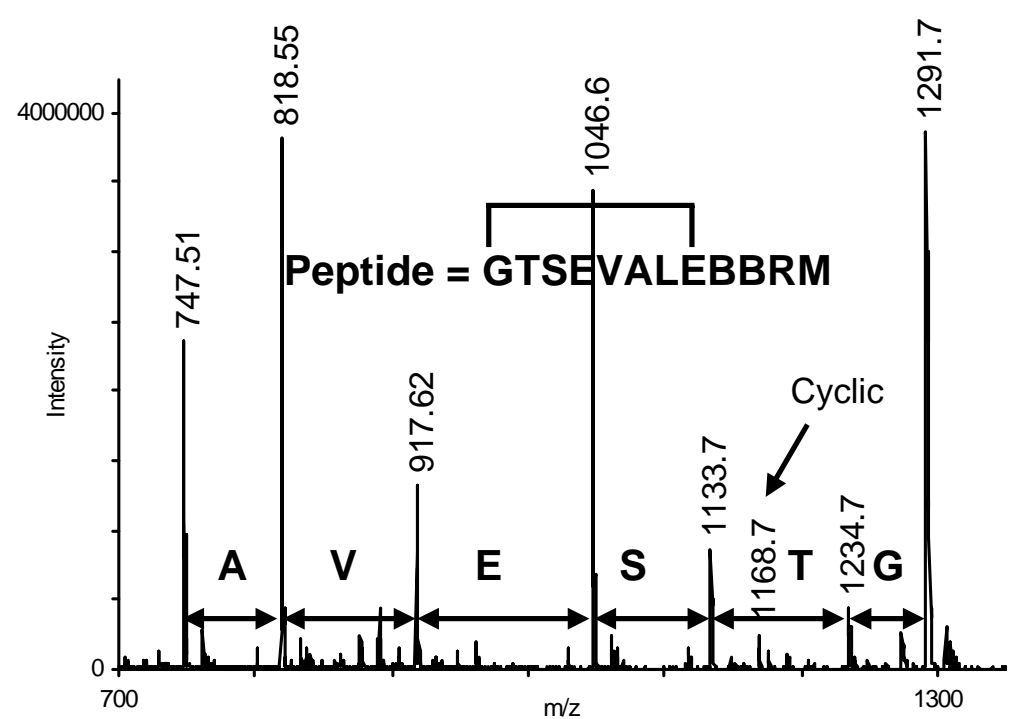

Z:ISang HoonIMaldi datal1010SJ101005\0_L13\1\1SReflpdatal1|1r

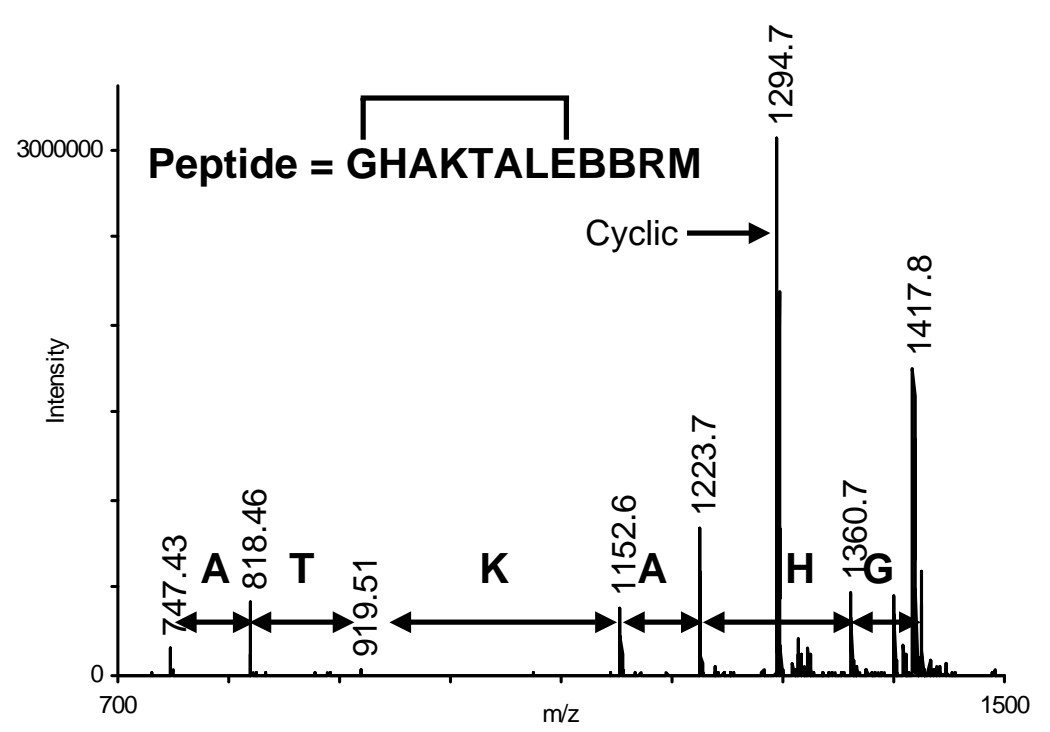

Z:ISang HoonIMaldi datal1010SJ101005।0_L15\1\1SReflpdatal111r

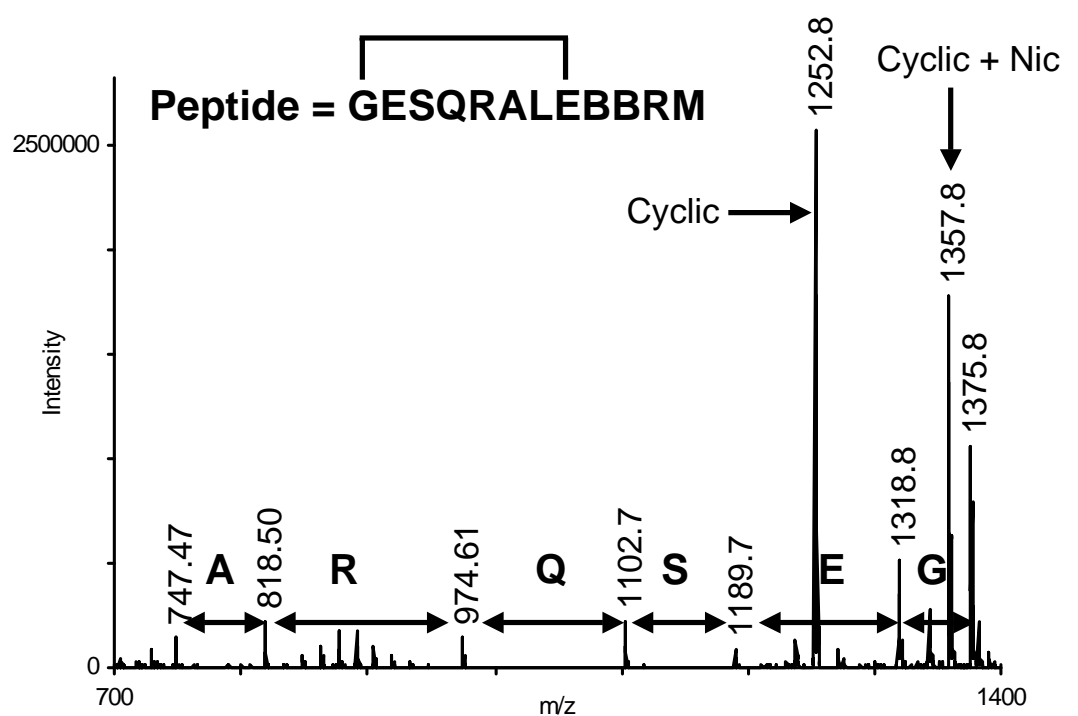

Z:ISang HoonIMaldi datal1010SJ101005I0_L14I1\1SReflpdatal1|1r

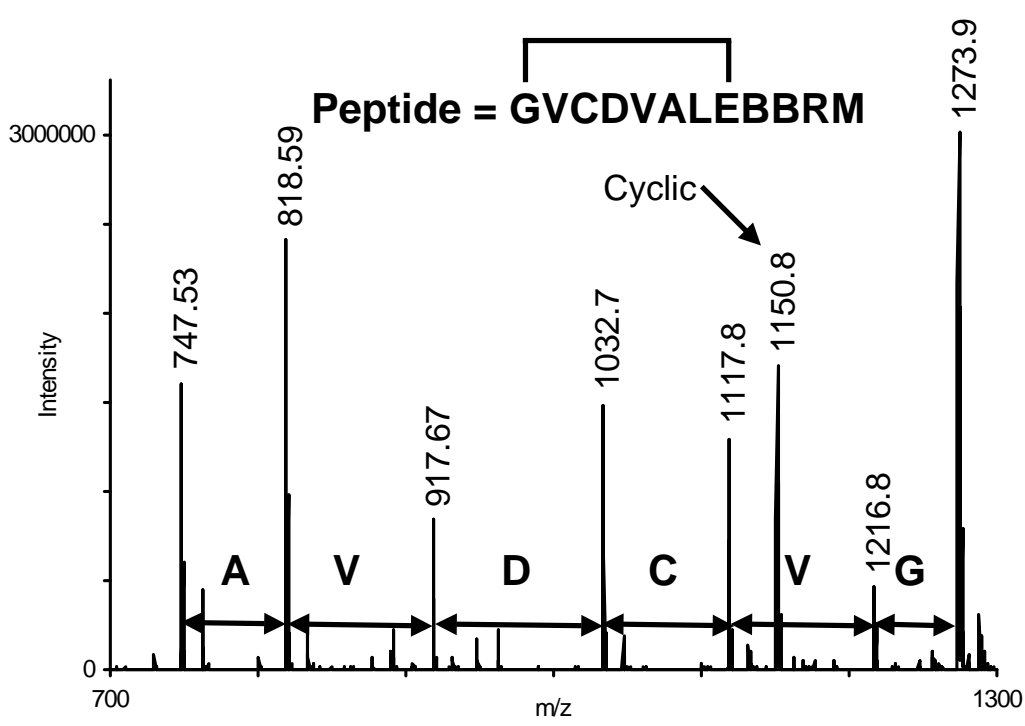

Z:ISang HoonIMaldi datal1010SJ101005।0_L1611\1SReflpdatal111r 
Figure S4 (cont'd)

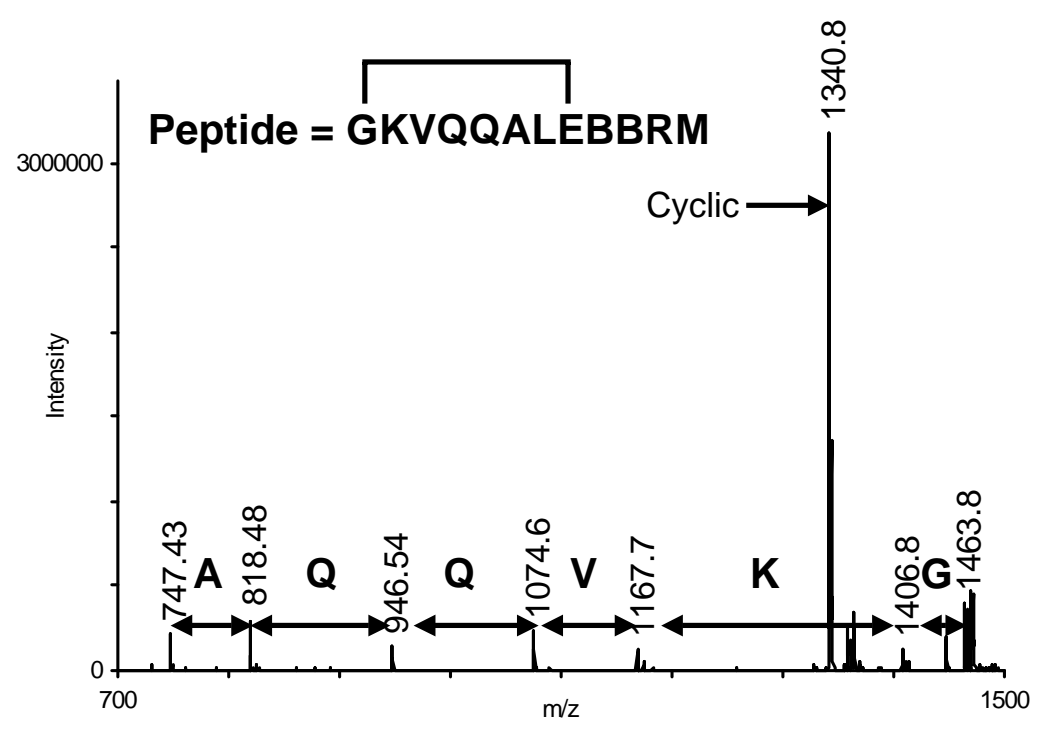

Z:ISang HoonIMaldi datal1010SJ101005I0_L17\1\1SReflpdatal1\1r

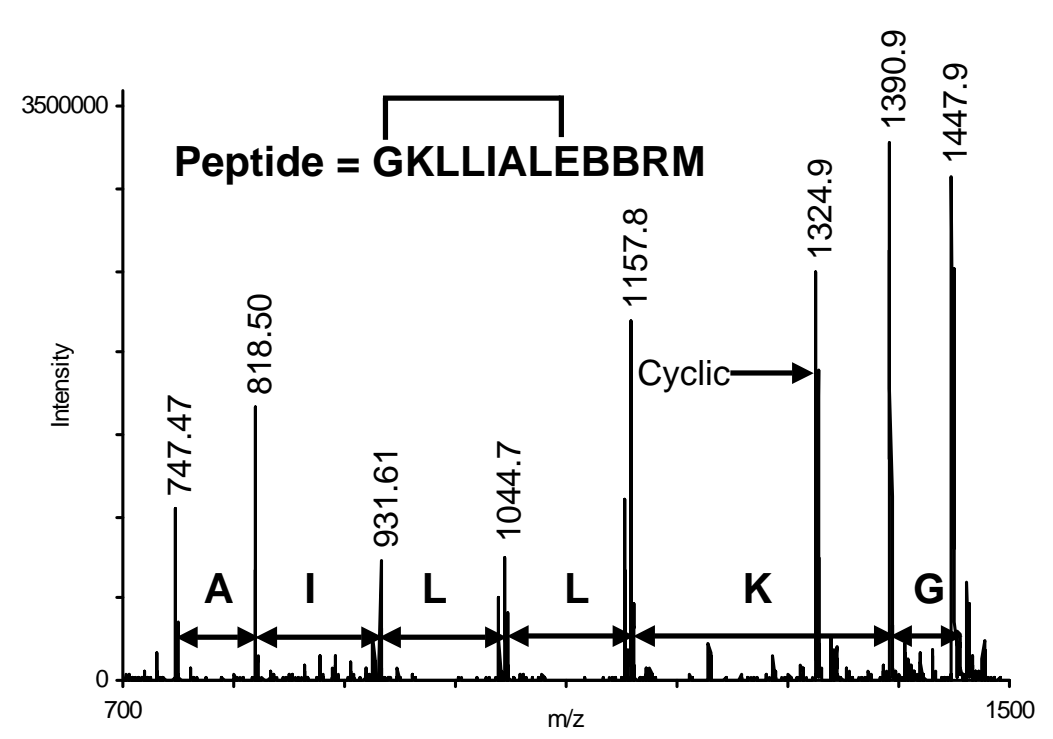

Z:ISang HoonIMaldi datal1010SJ10100510_L19\1\1SReflpdatal1\1r

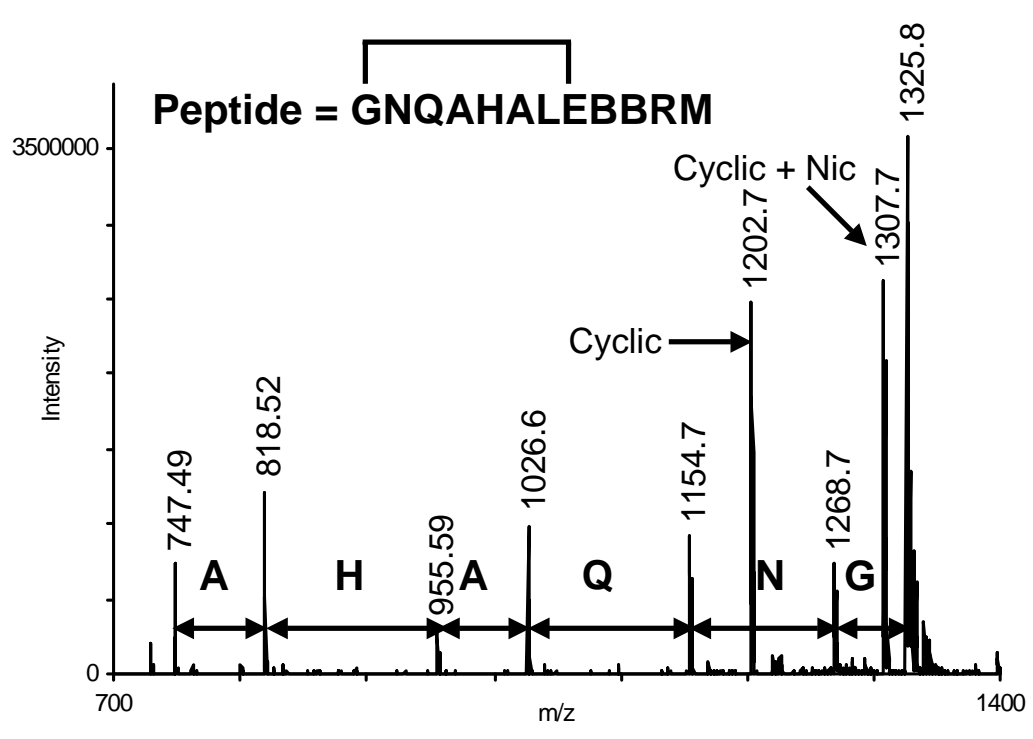

Z:ISang HoonlMaldi datal1010SJ10100510_L18\1\1SReflpdatal1\1r

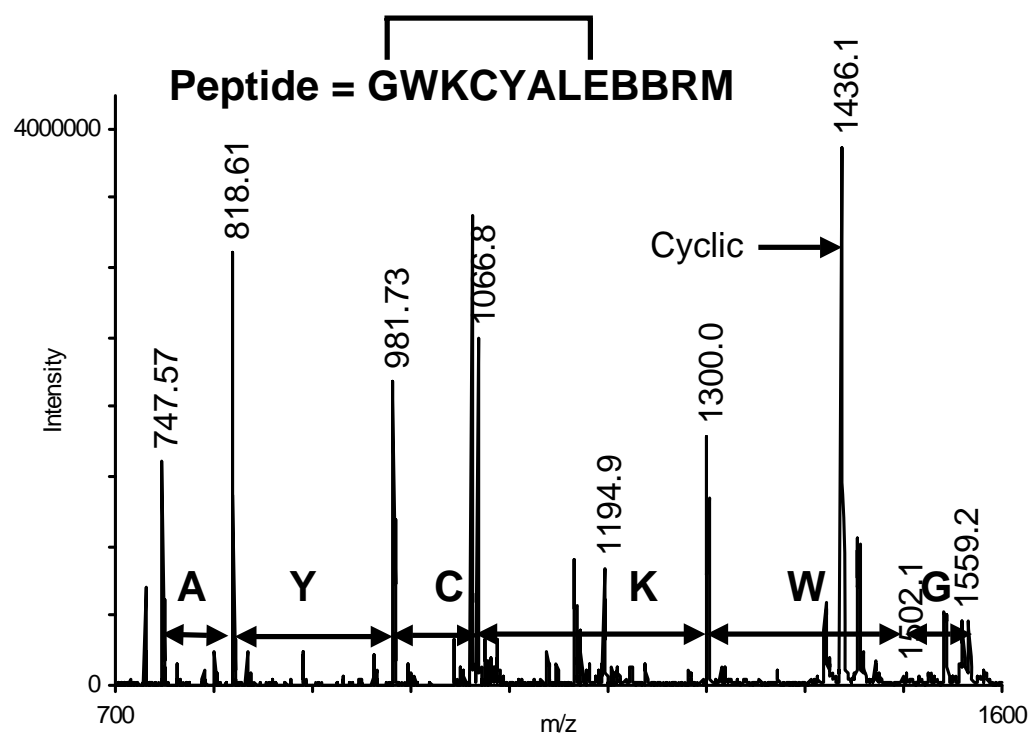

Z:ISang HoonlMaldi datal1010SJ101005I0_L2011\1SReflpdatal111r 


\section{Figure S5}

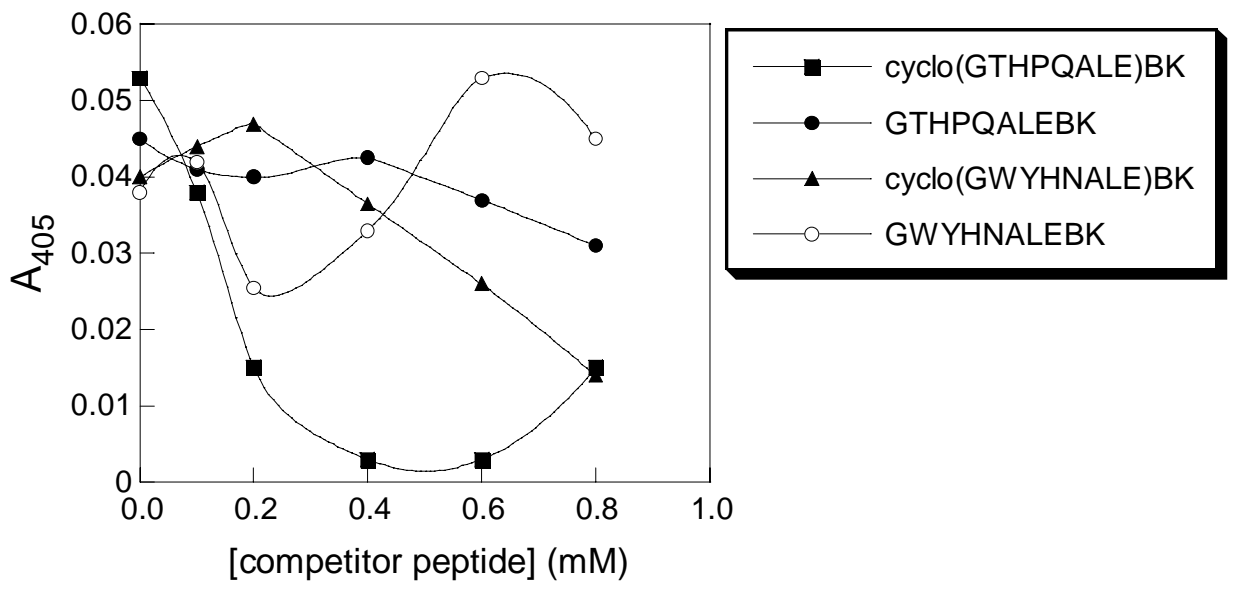


Figure S6

a

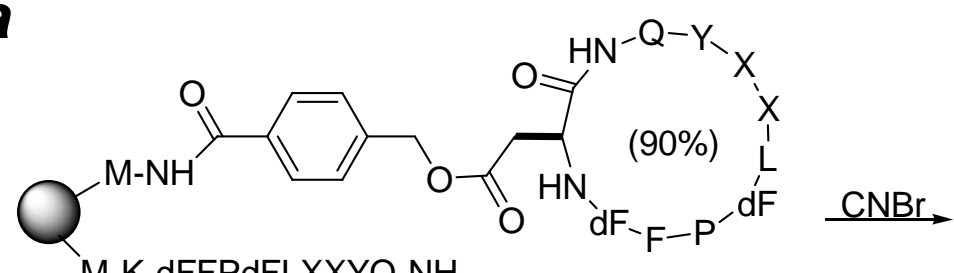

M-K-dFFPdFLXXYQ-NH ${ }_{2}$

$\mathrm{R} \quad(10 \%)$
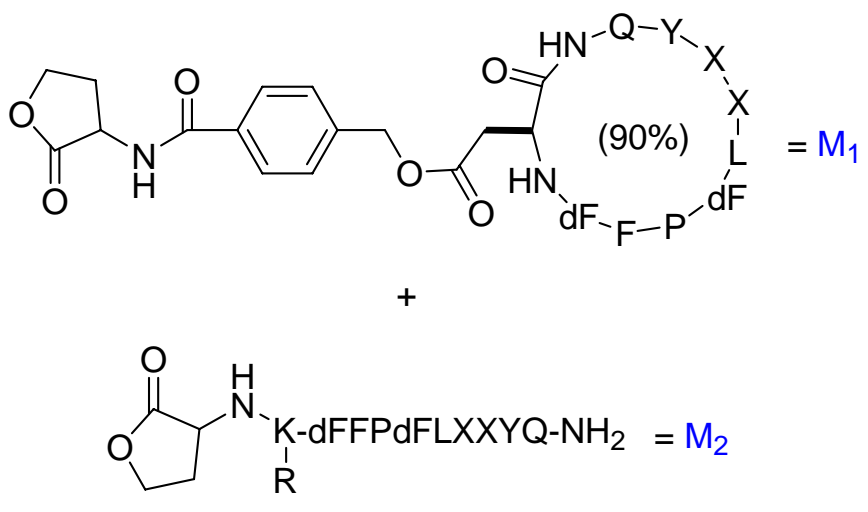

$(10 \%)$

b

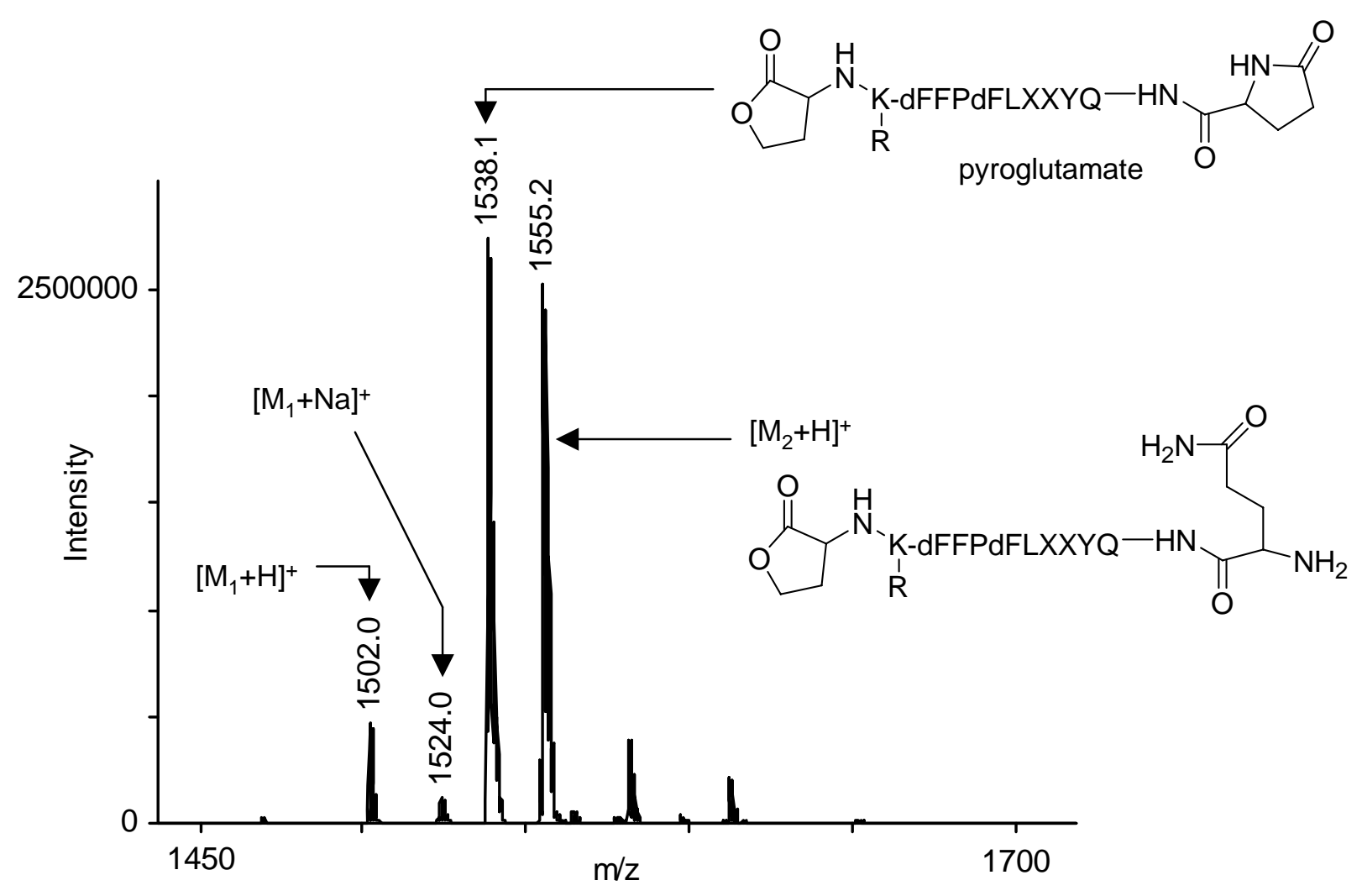




\section{Figure S6 (cont'd)}
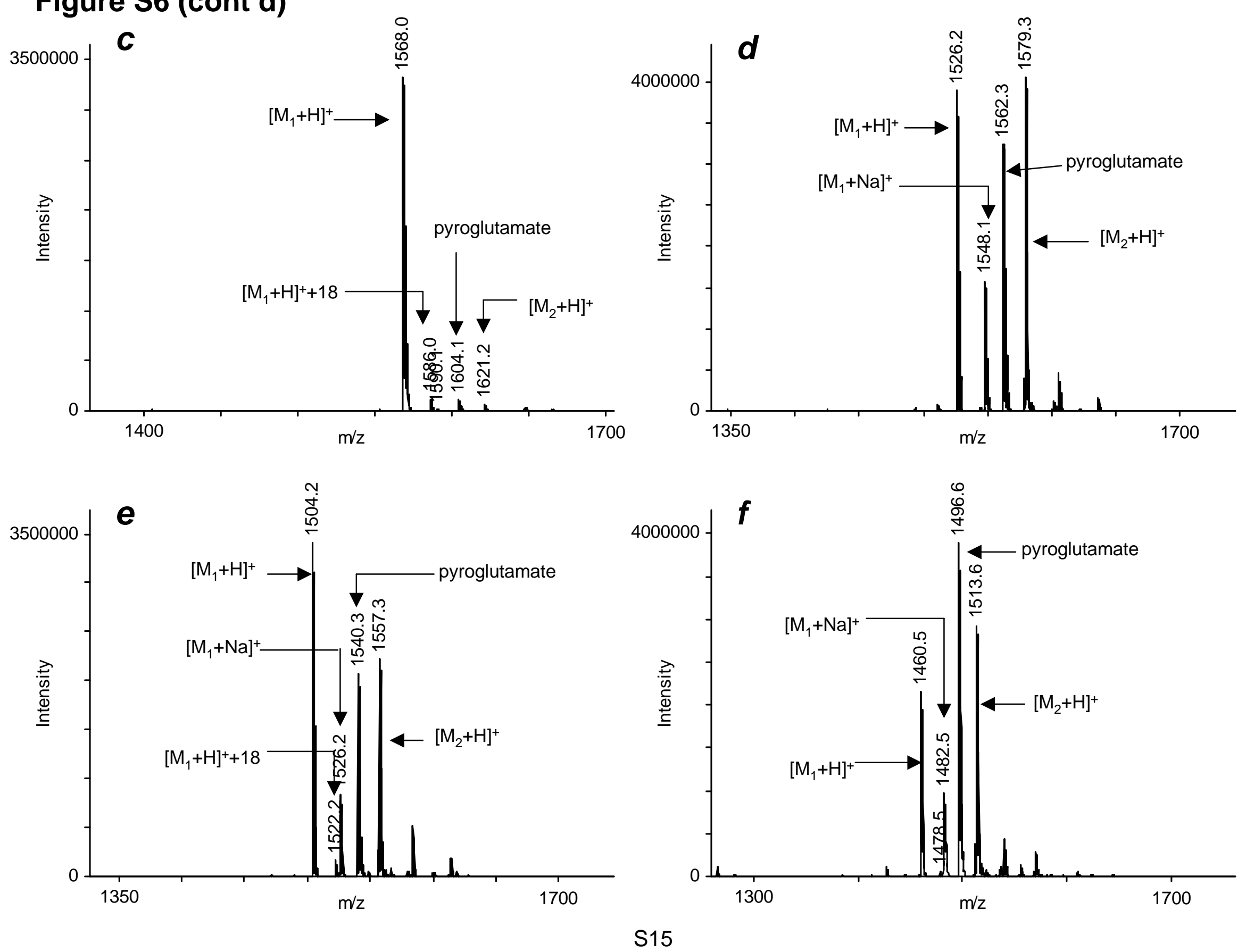
Figure S7. HPLC analysis of Tyrocidine A analogs
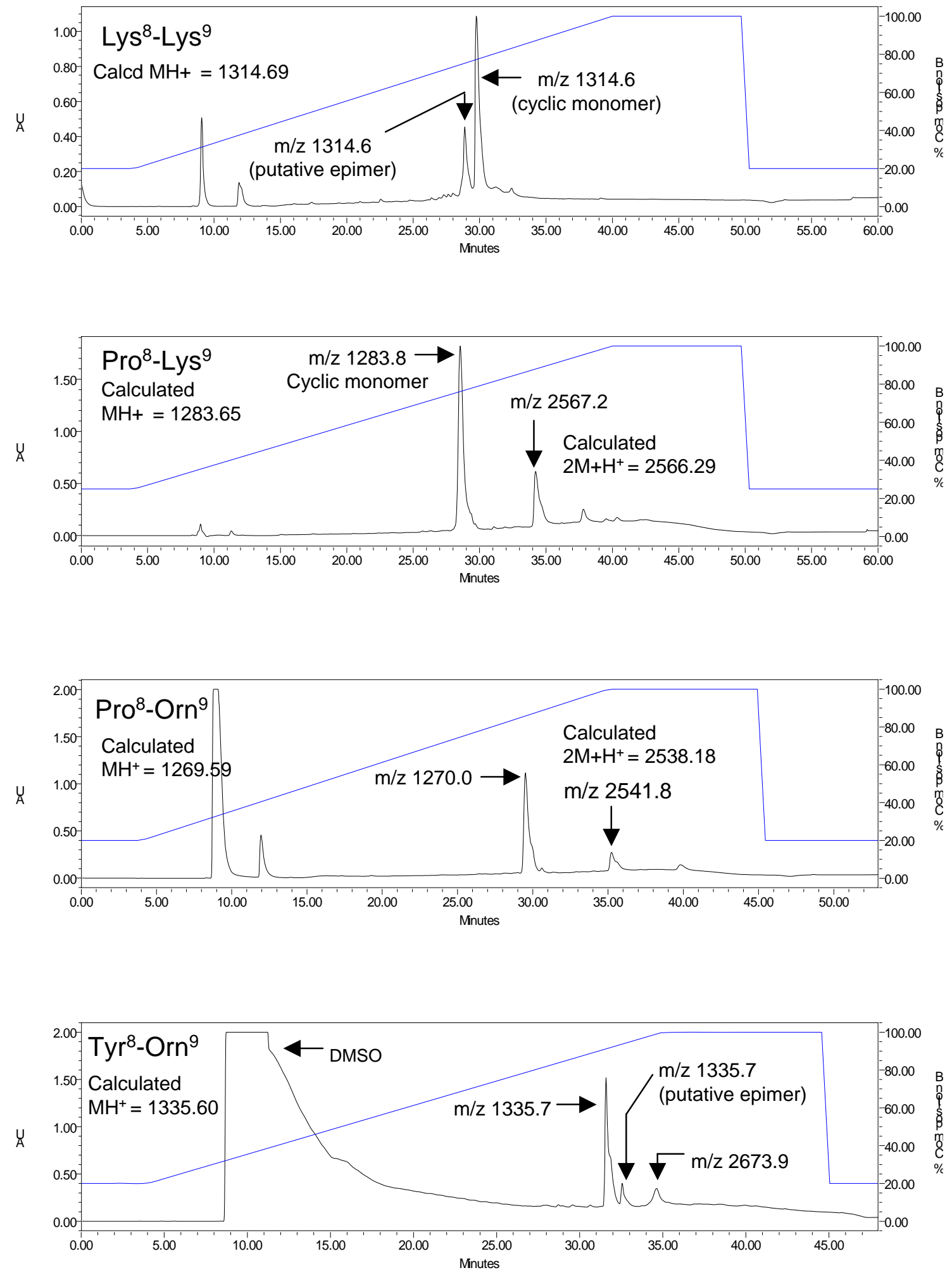
Figure S7 (cont'd)
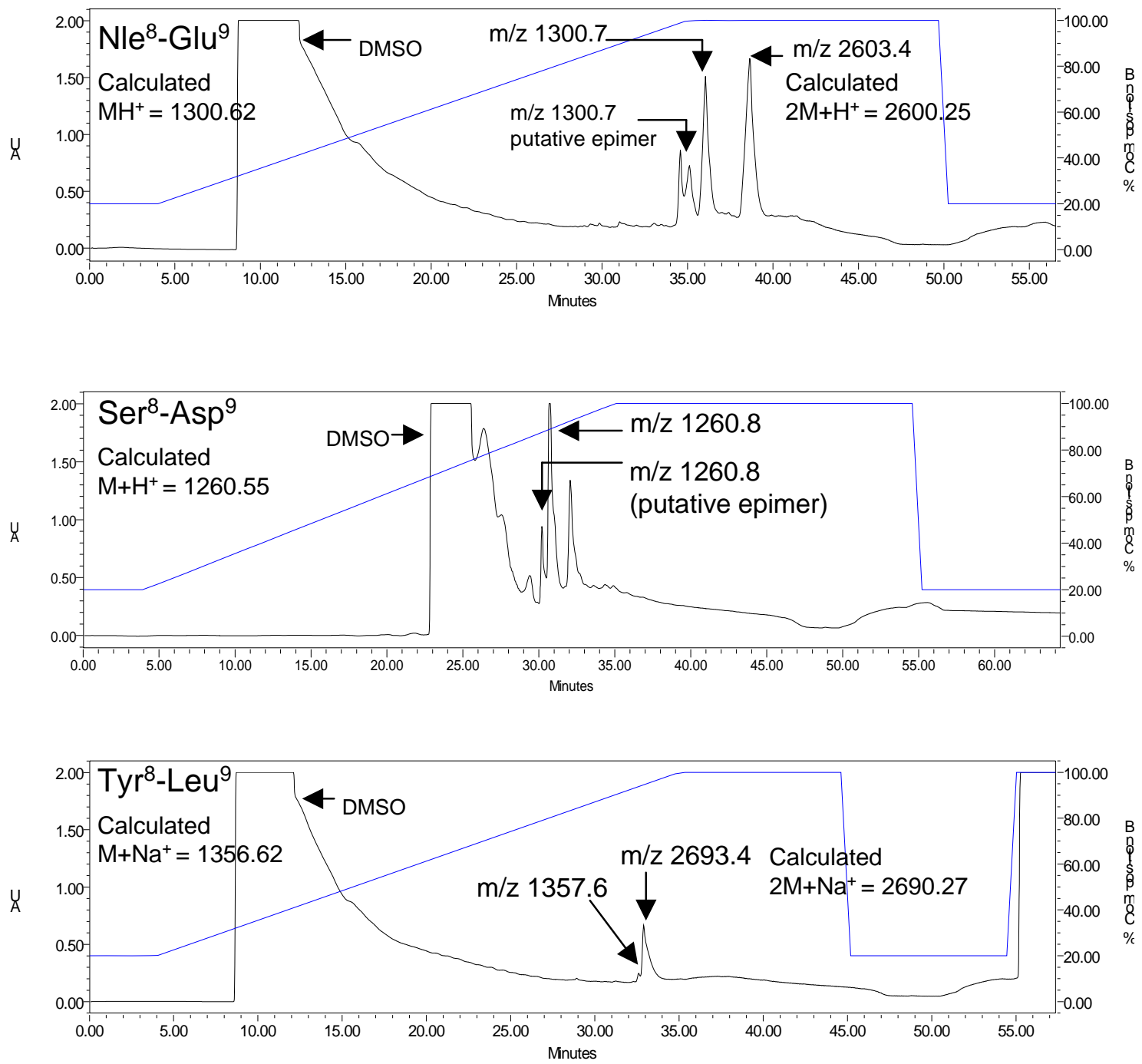

The absence of cyclic monomer in chromatogram is likely due to its very poor solubility in aqueous solution and thus unsuccessful injection.

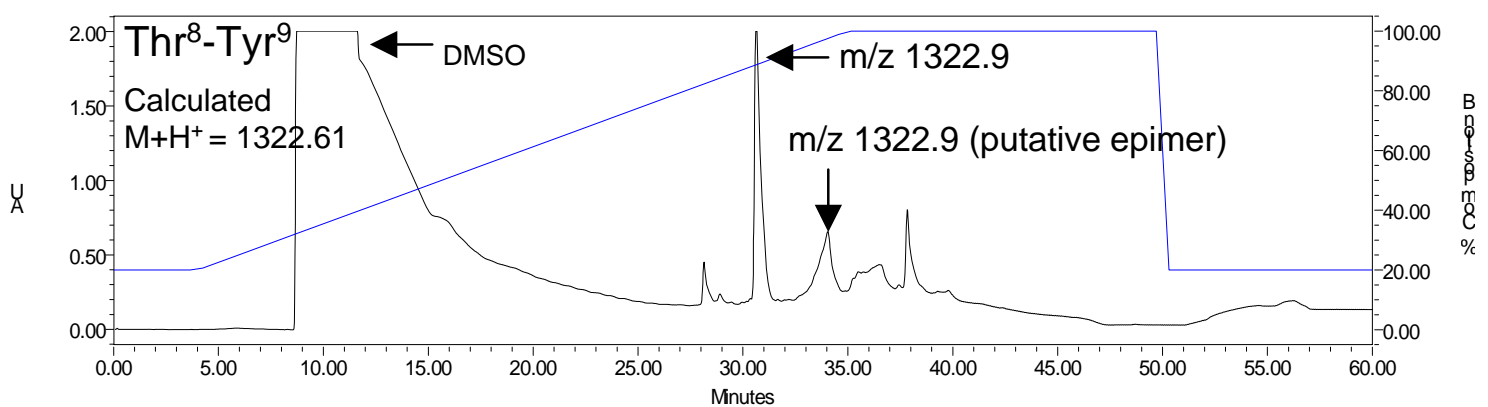

